\title{
Applications of quartering method in soils and foods
}

\author{
M. Campos-M. ${ }^{1}$, R. Campos-C. ${ }^{2}$ \\ ${ }^{1}$ (Faculty of Nutrition, Veracruzan University, Veracruz, Veracruz, México \\ ${ }^{2}$ (Faculty of Engineering, Veracruzan University, Boca del Río, Veracruz, México
}

\begin{abstract}
Sampling is a technique and a science. If the appropriate technique is followed it reduces the bulk mass and helps to respect the batch composition as best as possible. Non-representative sampling results in incorrect analysis. Soils and foods are materials constantly assessed. Subsampling methods, as conning and quartering are applied in solid samples. Then they could be functional in soils, and granular foods, like grains, cereals or nuts. The method is very dependent on the skill of the operator then great care must be taken when obtaining a sample by coning and quartering. It has some advantages, like the easiness, cleanness and inexpensiveness. But it is usually inaccurate and can provide non-representative samples.
\end{abstract}

Keywords - conning, food, quartering, sample, soil

\section{INTRODUCTION}

Regardless of how the sample is obtained, its composition must be representative of the bulk from which it was removed for analytical results to have any significance [1].

Non-representative sampling results in incorrect analysis, process failure, unacceptable products and customer dissatisfaction. It is essential that the samples selected for measurement should be representative of the bulk in particle size distribution and the relative fractions of their various constituents, irrespective of whether a physical or chemical assay is to be carried out, since these characteristics are frequently inter-dependent [2]. The less homogeneous the sampling volume is, the grater will be the sampling error [3].

To know the characteristics of any material, there are carried out laboratory test or quantitative and qualitative analysis. Soils and foods are materials constantly assessed. Once their properties and qualities are known, it is possible to propose and decide about its better use.

Commonly, which is expected from the result of an analysis, is that it is reliable and comparable with other laboratories.

Due to the multiple factors that get involved in the experimental development, which they belong to the environment and cannot be controllable for the analyst, it is necessary to reduce the variability as most as possible.

For it, the methodologies must be the officials. If a methodology is changed, it should be previously standardized, reducing at least the influence of discrepancy factors, like the equipment and the analyst on the result.

The quality of an analytical result is assessed by its accuracy and precision. The first is the distance between the result and a reference value, while the second is the distance among a set of repetitions.

If the data are uncertain, for example as a consequence of high random sampling errors (high sampling variances), the efficiency of statistical tests will be reduced by the high residual variances. It will invariably be more difficult and/or more costly to reach safe and reliable conclusions. Few chemometricians are aware of these facts [4]. Sampling is both a technique and a science. Sampling is fundamentally a mass reduction achieved by the appropriate technical means, but this operation must respect the batch composition as best as possible. We will see that there is no such thing as exact sampling: sampling itself generates errors and these errors must be controlled [4].

And sub-sampling is a procedure by which a small, representative sample is taken from a larger sample. It is an important technique in analytical chemistry when the large sample is not homogeneous.

Bulk material is considered any sample that arrives at the laboratory as a disturbed sampled or portions of intact samples that will be used for index testing. Three generic processing methods are available to manipulate the material. They are blending, splitting, and separating. Each has well defined objectives and can be performed using a variety of techniques and devices [5].

\section{QUARTERING METHOD}

The quartering method is for solid samples. At difference of these, to homogenize a liquid simple it needs fewer stages, in most of the cases waving could be enough. However, a solid sample 
has to be milled, mixed and sub-sampled by conning and quartering.

Quartering is a systematic splitting process. It can be performed on both dry and moist materials of virtually any size. Each quartering operation reduces the sample mass by one half. For s mall samples, the process can be performed on a glass plate using a straight edge. For large samples, use a splitting cloth and shovel [5].

For this procedure, the start is pouring a cone of material, which is then flattened as evenly as possible (Fig. 1).

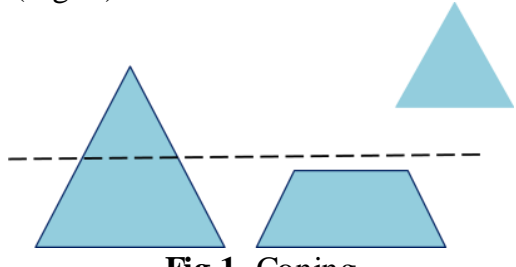

Fig 1. Coning

The material is then divided into quarters, whereupon two opposite quarters are discarded. The remaining two quarters are recombined and poured into another conical pile, which is then flattened and divided. The quartering process is continued until one is left with an amount of material that is the desired sample size. Great care must be taken when obtaining a sample by coning and quartering. When the initial powder sample is poured, it will undergo the full range of processes that result in segregation of particles according to their relative size. Because their flowability is the poorest, the finer particles will collect at the center of the cone, and the coarser particles will flow toward the edges of the cone. Hence, each wedge of a poured cone will become severely segregated by the act of pouring, making the process of subdivision and recombination critical. It is not unusual to obtain large standard deviations in particle-size results when the coning and quartering method is used to obtain a sample [1]. The milled solid is unfolded, and then formed a circle with four identical parts. That's the moment when using the imagination each slice is identified and called with the letters A, B, C and D (Fig. 2). That way, the next stage, is select two opposite slices, these can be the pair A-C, or B-C. Once the pair selected is separated, must be mixed again.

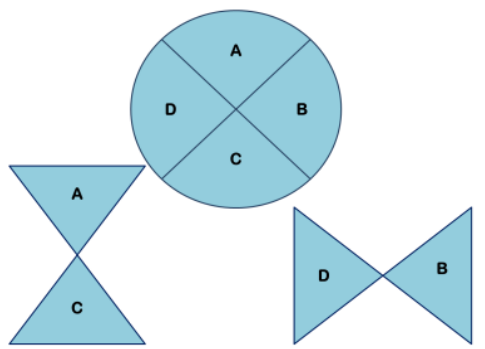

Fig 2. Quartering
This practice is based on the assumption that the heap is symmetrical and, since this is rarely so, the withdrawn sample is usually nonrepresentative. This method is no more accurate than scoop or thief sampling, that are simpler to carry out, but gross errors are to be expected. Coning and quartering should never be used with free-flowing powders [2].

The technique has the big advantage to be very simple and cleaning and it is easy to carry out [6]. But the method is very dependent on the skill of the operator. If coning and quartering is possible, this implies that the quantity of material to be divided is such that it can easily be moved by hand; it is just as easy to feed it into the hopper of a device such as a rotary sample divider in which increments are collected from a stream in an acceptable manner [7]. This method is well-suited for large lots of material, and can be conveniently done using shovels, or even front-end loaders for very large samples [8].

\section{I.1. APPLICATION IN SOILS}

An individual soil body, briefly called soil, occurs in the landscape side by side with other soils like pieces in a jigsaw puzzle. In many cases, and individual soil occupies a very large area of volume. The smallest representative unit of such a body is called a pedon. It is almost an impossible task to bring the whole soil body into the laboratory, and the most convenient way to conduct chemical analysis is to take soil samples from pedons, epipedons, or other horizons [3].

A study compared the most common homogenization techniques for different texture soils. Their results showed that riffle splitting was more efficient and had less loss of fines than cone and quartering, therefore, it is the recommended for soil homogenization [9].

Coning and quartering was compared with the usual sampling methods in prepared samples consisting of layers of sand, $\mathrm{NaCl}$ and magnetite. Then, it was associated with significantly higher variability and also took much longer to perform [10].

In 2004 there were not available standardized methods of reducing a large sample of hot mix asphalt and the quartering methods for aggregates were taken as reference, but these do not take into account the temperature at which the mix should be heated to ensure workability and the way to not affect the properties of the mixtu re within other details. It is for this reas on that LanammeUCR implemented an experimental design. It included the new quartering method for multiple sampling boxes and then measure the asphalt content and gradation with the ignition test for each subsample and also the maximum 
theoretical specific gravity was performed, it was shown that with this method it is possible to obtain representative subsamples with good repeatability and also found that the segregation of the mixture was eliminated using the gutter system that in one step the desired subsamples are obtained [11].

Table I. Quartering ap plications in soil research

\section{General Obje ctive}

To quantify the proportion of variability in total elemental composition by total X-ray fluorescence (TXRF) [12]

To examine the role of the extracts in causing soil water repellency [13]

\begin{tabular}{l} 
Subsampling \\
Soil samples were first air- \\
dried and passed through a 2- \\
mm sieve before sub sampling \\
to $10 \mathrm{~g}$ using coning and \\
quartering technique to ensure \\
homogeneity of the sample. \\
Samples were oven-dried at \\
20॰C and passed through a 2- \\
mm sieve prior to further \\
analysis. All soils were of \\
medium sand text ure, with a \\
clay content <0.1\%. \\
To reduce variability between \\
subsamples, the coning and \\
quartering method was used. \\
The resulting cones were then \\
coned and quartered until each \\
subsample was 40-50 g in \\
size. \\
The >2-mm fraction of the \\
ISU soil, which formed small \\
balls because the soil was \\
moist, was lightly broken \\
apart using a mortar and pestle \\
and then resieved. This \\
process was repeated until all \\
the soil had been sieved. Both \\
soils were stored in large \\
plastic containers covered \\
with a porous plastic mesh \\
that allowed them to air dry. \\
The <2-mm soil fraction (the \\
original or bulk soil) was \\
subsampled either by coning \\
and quartering or by using a \\
Humboldt splitter. \\
\hline
\end{tabular}

A study assessed and compared the performance of a mechanical sampler and a traditional sampling method in a bulk sample of iron chips and sand mixture. Using a riffle sample splitter for sampling procedure will give more accurate results with higher efficiency than when the coning and quartering sampling technique is being used, the sub-samples that will be obtained will also be more homogeneous and will more closely represent the bulk or parent sample than when coning and quartering technique is adopted. Although, the coning and quartering technique is more economical, it does not assure accuracy [15].

Practical methods of subsampling do not select these grains on an entirely random basis. Rotary subsampling and chute splitting were found to be more reliable methods of subsampling than cone and quartering or random spoon sampling. Variability between subsamples is shown to depend not only on subsampler design, but also on the precise details of the procedure adopted, and the physical properties of the sample itself [16].

Table I shows some applications of conning and quartering subsampling in soil research.

\section{I.2. APPLICATIONS IN FOODS}

In food analysis, sampling is first practice. If it is well done, it will contribute to yield reliable results. Food analysis is important to know nutritional composition foods, like protein amount, lipids or fiber, to know some particular constituent amount, alike a nutrient, as water or bioactive compounds.

In foods for mycotoxin analysis, if the sampling plan is faulty, then the analytical results obtained can indicate that the batch contains less than the permitted level of aflatoxin, whereas the mean value may be in excess of the limit. Alternatively, the results may indicate that the batch contains more than the permitted level, although the mean may be the less. In the first case there is a potential health hazard and hence a consumer risk, whereas in the latter case there is an economic loss to the producer, named producer risk [17]. Some authors consider that conning and quartering sampling can be performed to analyze aflatoxins in processed materials, because they are distributed in a relatively homogeneous manner, unlike in unprocessed materials [18].

In addition this simple technique is commonly used in many laboratories [18].

A number of methods of varying complexity can be used for sub-sampling an aggregate sample after it has been thoroughly mixed for grains of different sizes and quality. These include 'coning and quartering' and sample dividers, such as a cone-shape divider, a rotatory mechanical divider or a riffle divider. Details for using such equipment are given in ISO24333; the only constraint is that riffle dividers should not be used for samples of less than $2 \mathrm{~kg}$ [19].

Table II shows some applications of conning and quartering subsampling in food research.

Table II. Quartering applications in food research

\begin{tabular}{|l|l|}
\hline \multicolumn{1}{|c|}{ Aim } & \multicolumn{1}{|c|}{ Subsampling } \\
$\begin{array}{l}\text { To update the sampling } \\
\text { mycotoxins in grains } \\
{[20]}\end{array}$ & $\begin{array}{l}\text { Sample preparation: Conic divider } \\
\text { (like Boerner): Samples are fed by } \\
\text { gravity from a hopper down the } \\
\text { outside of a smooth cone divided at } \\
\text { the bottom into 36 streams of grain } \\
\text { which are grouped into two outlets. } \\
\text { Samples of free flowing grain may } \\
\text { be rapidly divided into smaller } \\
\text { subsamples. The utilization of } \\
\text { quartering devices should be kept } \\
\text { only as a last resource as it is } \\
\text { advised by FAO. It is of utmost }\end{array}$ \\
\hline
\end{tabular}




\begin{tabular}{|l|l|}
\hline & $\begin{array}{l}\text { importance that the final part to be } \\
\text { analyzed (analytical sample or } \\
\text { analytical portion) represents the } \\
\text { original sample. }\end{array}$ \\
\hline $\begin{array}{l}\text { To examine the } \\
\text { concentration of total } \\
\text { arsenic in rice samples } \\
{[21]}\end{array}$ & $\begin{array}{l}\text { After quartering, sample pre- } \\
\text { treatment followed Codex } \\
\text { Alimentarius recommendat ions. } \\
\text { Fifty grams of samples was } \\
\text { individually milled, homogenized } \\
\text { and sieved (0.25 mm) with an } \\
\text { electric ultra-centrifugal mill } \\
\text { (Retsch ZM200 with DR100 } \\
\text { auto-sampler) at 6000 rpm. Then, } \\
\text { samples were placed into clean 50 } \\
\text { mL conic tubes (Falcon®BD) until } \\
\text { total and chemical speciation } \\
\text { analysis. }\end{array}$ \\
\hline $\begin{array}{l}\text { To determine the total } \\
\text { selenium concentrations } \\
\text { in } \\
\text { selected } \\
\text { consumption food [22] }\end{array}$ & $\begin{array}{l}\text { The samples selected were } \\
\text { representative of the Argentina diet } \\
\text { since all correspond to trademarks } \\
\text { whose market products from a large } \\
\text { region that includes the food- } \\
\text { producing provinces analyzed in the } \\
\text { work. Beef, chicken breast, fish, } \\
\text { eggs, and pasta were milled and } \\
\text { homogenized in a food processor } \\
\text { and then sub-sampled for analysis. } \\
\text { Rice and wheat flour were sampled } \\
\text { by mixing and quartering. }\end{array}$ \\
\hline
\end{tabular}

The mycotoxin ochratoxin A (OTA) has neurotoxic, teratogenic and immunosuppressive properties. Sampling is a special challenge in the determination of OTA in cereals and cereal-based foods due to the heterogeneous distribution of OTA in food items. OTA is heterogeneously distributed within bulk lots of food items, as well as amongst individual items. This heterogeneity affects raw cereal grains as well as processed cereal-based foods that are available at retail level. Sampling is the main contributor to the overall variance of OTA analytical results and it contributes to measurement of uncertainty about the true value of OTA in food item lots. Unfortunately there are currently no data comparing the effects of various subsampling techniques on the variance of OTA analytical results [23].

\section{CONCLUSION}

Both soil and food analyses require a representative sample.

Several authors have compared different subsampling methods, mainly in soils. Then, they have concluded that the use of a rotatory sampling device, or spinning riffler, is probably the best instrument available for the subdivision of powders having heterogeneous particle-size distributions [1], [9], [10]. While conning and quartering are not recommended because they don't assure accuracy and generates higher sample variability. Although they have the advantage to be clean, easy and lowcost. Furthermore, in foods there are not comparisons among subsampling methods, but conning and quartering are usually applied to know the toxin and particular components concentrations.

\section{REFERENCES}

[1] H. Brittain, "The Problem of Sampling Powdered Solids," Pharmaceutical technology, pp. 67-73, 2002.

[2] T. Allen, Powder Sampling and Particle Size Determination. Els evier, 2003.

[3] K. H. Tan, Soil Sampling, Preparation, and Analysis, Second Edition. CRC Press, 2005.

[4] P. Gy, "Sampling of discrete materials - a new introduction to the theory of sampling: I. Qualitative approach," Chemometrics and Intelligent Laboratory Systems, vol. 74, no. 1, pp. 7-24, 2004.

[5] J. T. Germaine and A. V. Germaine, Geotechnical Laboratory Measurements for Engineers. John Wiley \& Sons, 2009.

[6] Institute for Health and Consumer Protection, Guidelines for sample preparation procedures in GMO analysis. Lu xembourg: Publications Office, 2014.

[7] T. Allen, Particle size measurement. Springer, 2013.

[8] "Microsoft Word

CM3820.2009.Sa mpling.doc

CM3820_2009_Sampling.pdf."

[9] B. A. Schumacher, K. C. Shines, J. V. Burton, and M. L. Papp, "Comparison of three methods for soil homogenization," Soil Science Society of America Journal, vol. 54, no. 4, pp. 1187-1190, 1990.

[10] R. W. Gerlach, D. E. Dobb, G. A. Raab, and J. M. Nocerino, "Gy sampling theory in environmental studies. 1. Assessing soil splitting protocols," Joumal of Chemometrics, vol. 16, no. 7, pp. 321-328, Jul. 2002.

[11] M. J. Acuña and F. E. Arrieta, "Método de reducción de muestra para ensayos de laboratorio en mezcla asfáltica en caliente," Métodos y Materiales, vol. 4, no. 1.

[12] E. K. Towett et al., "Total elemental composition of soils in Sub-Saharan Africa and relationship with soil forming factors," Geoderma Regional, vol. 5, pp. 157-168, Aug. 2015.

[13] "DOI: 10.1071/SR04091 - Doerr2005-extractAJSR.pdf." .

[14] L. M. Choate, J. F. Ranville, A. L. Bunge, and D. L. Macalady, "Dermally adhered soil: 1. Amount and particle-size distribution," Integrated Environmental Assessment and Management, vol. 2, no. 4, pp. 375-384, Oct. 2006.

[15] "ijet An Assessment of Laboratory Sample Splitting 8487721476714559.pdf." 
[16] C. E. Mullins and B. J. Hutchison, "The variability introduced by various subsampling techniques," Journal of Soil Science, vol. 33, no. 3, pp. 547-561, Sep. 1982.

[17] K. Jewers et al., "Methodological developments in the sampling of foods and feeds for mycotoxin analysis," Journal of applied bacteriology, vol. 67, no. s18, 1989.

[18] E. V. Reiter et al., "Uncertainty from sampling in measurements of aflatoxins in animal feedingstuffs: application of the Eurachem/CITAC guidelines," The Analyst, vol. 136, no. 19, p. 4059, 2011.

[19] "Grain Outlook grain_sampling_guide_2013.pdf." [Online]. Available:

https://cereals .ahdb.org.uk/med ia/248889/grai n_sampling_guide_2013.pdf. [Accessed: 27Dec-2016].

[20] H. Fonseca, "Sampling plan for the analysis of aflatoxin in peanuts and corn: an update," Brazilian Journal of Microbiology, vol. 33, no. 2, pp. 97-105, Jun. 2002.

[21] B. L. Batista, J. M. O. Souza, S. S. De Souza, and F. Barbosa, "Speciation of arsenic in rice and estimation of daily intake of different arsenic species by Brazilians through rice consumption," Journal of Hazardous Materials, vol. 191, no. 1-3, pp. 342-348, Jul. 2011.

[22] M. Sigrist, L. Brusa, D. Campagnoli, and H. Beldoménico, "Determination of selenium in selected food samples from Argentina and estimation of their contribution to the $\mathrm{Se}$ dietary intake," Food Chemistry, vol. 134, no. 4, pp. 1932-1937, Oct. 2012.

[23] S. A. Tittlemier, E. Varga, P. M. Scott, and R. Krska, "Sampling of cereals and cereal-based foods for the determination of ochratoxin A: an overview," Food Additives \& Contaminants: Part A, vol. 28, no. 6, pp. 775785, Jun. 2011. 